\title{
APPRAISAL AS AN EFFECTIVE MEANS OF ASSESSING \\ STUDENT PERFORMANCE IN CLINICAL LEGAL EDUCATION
}

\section{AT THE UNIVERSITY OF PORTSMOUTH}

Pat Heather Feast, Principal Lecturer, School of Law, University of Portsmouth,

United Kingdom

The aim of this paper is to advance the notion that using the workplace model of appraisal is an effective method of assessing students who undertake clinical legal education (CLE). It is the belief of the team working in the law clinics at the University of Portsmouth that appraisal provides students with both praise and constructive criticism and the necessary information to enable them to improve their performance while working in the University of Portsmouth clinics. Giving feedback on a regular basis via the appraisal system motivates the students to strive for improvement and helps them to meet the challenges of achieving excellence. At the University of Portsmouth, staff, students and, in some cases, the representatives of our partner organisations work together in our appraisal system to tackle any barriers to student success within our CLE progammes.

Keywords: clinical legal education; appraisal; assessment and feedback 


\section{Introduction}

Changes in legislation brought about by the Legal Aid, Sentencing and Punishment of Offenders Act 2012 (LASPO) have resulted in an increased demand for free legal advice in many areas of the law, including social welfare law. University law clinics are one means of meeting some of that demand. In the 2013 Consultation paper 'Transforming Legal Aid', Chris Grayling, the then Lord Chancellor and Secretary of State for Justice, stated that "[i]n the past decade our legal aid bill has risen [and] is now one of the highest in the world, costing the taxpayer nearly $£ 2$ bn each year [and] reforms should deliver savings of some $£ 320$ m p.a. in $2014-15^{\prime \prime} .{ }^{1}$ Response from the not for profit sector to the reform was swift and research on the impact of budget reductions across the sector have resulted in the prediction of some particularly gloomy outcomes, including stagnation in the legal process due to the question of "how case law will be made" ?2

At a recent Association of Law Teachers Conference, a colleague and I presented a paper which investigated the role of Clinical Legal Education (CLE) activities in universities within the wider legal landscape. ${ }^{3}$ After an examination of whether universities are 'filling the gap' left by reductions in legal aid or whether

\footnotetext{
${ }^{1}$ Ministry of Justice, Transforming Legal Aid: delivering a more credible and efficient system (Ministry of Justice Consultation Paper CP14/2013).

${ }^{2}$ Bill Sargent Trust, Counting the cost: advice services and the public spending reductions, 2013, p. 48

${ }^{3}$ P. Feast and V. Brown, "Filling the Gap" (ALT Annual Conference, Portsmouth, April 2017).
} 
using accepted pedagogic theories of experiential learning CLE simply meets universities strategic aims of education and employability it was clear that university clinical activities are to a large extent having an impact on both. Whether the gradual increase in the number of law schools across the $\mathrm{UK}^{4}$ who offer students the opportunity of providing free legal advice to the local community via advice clinics is a response to legislative changes or whether universities see CLE as a positive educational tool to aid employability is still a matter for debate. Regardless of the reason however they certainly offer a useful service to the public. Their primary purpose as far as the University of Portsmouth is concerned is to meet the University's Education Strategy ${ }^{5}$ of providing intellectual challenge, enhance skills acquisition and embody academic excellence through courses that are practice informed and that engage students in research and innovation and to ensure that every student participates in career enhancing activities to learn through experience and to strengthen their personal development and to act as a vehicle for students to acquire professional legal skills. At the fore of CLE is the development of professional, academic and social skills relating to interviewing, problem-solving, team-working, legal

\footnotetext{
${ }^{4}$ See e.g. D. Carney, F. Dignan, R. Grimes, G. Kelly and R. Parker, 'The LawWorks Law School Pro Bono and Clinic Report 2014' Available at https://www.lawworks.org.uk/sites/default/files/LawWorks-student-pro-bonoreport\%202014.pdf (accessed 1 June 2017).

${ }^{5}$ University of Portsmouth Education Strategy 2016-2020
} 
research and legal writing. This process is enhanced by a reflective analysis of the clients' cases and by discussions with supervisors and fellow students. The experience is similar to that of a solicitor advising his or her client but, since the primary aim of any clinic activity is student education, time is generally structured to enable students to fully learn from the experience. At the University of Portsmouth, clinics are generally supervised by a practising solicitor who ensures that any advice given is equivalent to that of a professional solicitor.

\section{CLE at University of Portsmouth}

Having undertaken an academic year of training, the students working on Portsmouth's assessed CLE programmes are fully equipped to engage in activities which would otherwise be prohibitive under the constraints of a traditional degree where the emphasis is on coursework and examination. Portsmouth's CLE programmes enable students to experience legal casework and undertake legal analysis within a structured framework, overseen (albeit from a distance) by an experienced member of staff who is also a practising solicitor. The 'light touch' supervision reduces the reliance on staff for an immediate answer and places responsibility on the student to apply knowledge previously gained, thus providing continuous opportunities for reflection. ${ }^{6}$

\footnotetext{
${ }^{6}$ R. Grimes and J. Gibbons, "Assessing Experiential Learning - Us, them and the Others" (2016) 23 International Journal of Clinical Legal Education 114.
} 


\section{Role of the Supervisor}

As Ziegler suggests,

[a]s 'expert', the clinical supervisor gives students authoritative information without necessarily demonstrating the thought processes or skills used to obtain them. As 'model' the teacher demonstrates the skills and thought processes of a good clinician providing an 'open book' that learners may watch and imitate. As a 'facilitator', the teacher guides the student in doing the actual work while focusing on helping the student to acquire and analyse information. ${ }^{7}$

The role of the Supervisor as 'expert' at Portsmouth is to support students as they research information for their client. The supervisor, who is a practising solicitor, checks the results of research for accuracy and relevance and gives direction for further study. Observation provides the student with an opportunity to learn how to ascertain key facts and how to come to a conclusion which can be given to the client with confidence. As 'model', the supervisor shares this best practice across the group. As 'facilitator', the supervisor stands back and allows students to learn from their own experiences, giving guidance in a supported environment without fear of repercussions. At Portsmouth, the role of the clinic supervisor is probably more closely linked to the role identified here as 'facilitator'. The aim is

\footnotetext{
${ }^{7}$ A. Ziegler, "Developing a System of Evaluation in Clinical Legal Education" (1992) 42 Journal
} of Legal Education 575, 583. 
to encourage students to identify theoretical models and to use these in a practical setting which as Ziegler suggests "guides the student in doing the actual work while focusing on helping the student to acquire and analyse information".$^{8}$

The model adopted at Portsmouth also resembles that propounded by Ziegler in that it focuses on student involvement and participation and that by facilitating learning rather than teaching, the supervisor encourages the student to be confident in his or her interaction with the client. Supervision will gradually be reduced to a point where the supervisor will only check to evaluate the advice and information for accuracy before it is delivered to the client.

\section{Assessment}

What must be acknowledged is that assessment in higher education must not only provide certification but must also support student learning. ${ }^{9}$ Such assessment can, of course, be in the traditional format, i.e. examinations or coursework and as CLE programmes at the University of Portsmouth are part of the curriculum it is vital that assessment is rigorous and in line with University of Portsmouth regulations. However, the team working on the programmes felt we needed to go further than this as in our view, students should be viewed as

\footnotetext{
${ }^{8}$ Ibid.

${ }^{9}$ D. Bouod, D and N. Falchikov, "Redesigning assessment for learning beyond higher education" in Higher education in a changing world: Proceedings of the $28^{\text {th }}$ HERDSA Annual Conference, Sydney, 3-6 th July, 34-41.
} 
future employees rather than students studying how to become a lawyer and that CLE provides an opportunity to consider assessment more closely aligned to the type of work undertaken. Once a student enters the interview room with a member of the public that student is, for all intents and purposes, a lawyer and the client sitting in front of them expects (and why should he or she not) that the information and advice he or she is given is reliable because that lawyer is trained to act in this capacity.

As Sylvester appreciates, "[c]linic is a constructivist teaching methodology - it can deliver discipline and procedural legal knowledge but more often its role is emphasised in terms of teaching legal and intellectual skills and as a method of inculcating professional values and ethics through its traditional involvement in social justice".${ }^{10}$ Assessing these skills, values and ethics necessitates the use of a different assessment model which emphasises the practical element of this assessed unit.

Assessing students on their individual performance as they interact with clients is however not reliable as each client may bring to the clinic either very complex or very straightforward issues and therefore like for like skills are not being tested. The challenge for the team in assessing how well a student has performed/is performing in this environment was how to assess achievement

${ }^{10}$ C. Sylvester, "Through a Glass Darkly: Assessment of Real Client, Compulsory Clinic in an Undergraduate Law Programme" (2016) 23 International Journal of Clinical Legal Education 32, 37. 
when trying to replicate a dynamic and realistic working environment. For this reason the team decided to introduce appraisal as a means of assessing student achievement and a comparison to its use in the workplace is useful here.

Appraisal has the dual purpose of appraising performance and achievement and providing guidance for future activity and therefore appraising performance can become an accurate and effective assessment tool. In the workplace, an appraisal is a meeting where the manager/supervisor assesses the performance of the individual against a set of pre-agreed targets. There is a great deal to be gained from a well conducted appraisal as it can be a celebration of achievement, help to identify good performance and focus on areas for improvement. In the workplace it can also help to make decisions about career progression by discussing the individual's aspirations for the coming year. Writing on the Job.ac.uk website, Neil Harris poses the question 'Why do we need Appraisal?" Harris states "[a]ccording to the Chartered Institute of Personnel and Development (CIPD), $87 \%$ of employers use some form of individual annual appraisals, $27 \%$ do them twice a year and $10 \%$ more often than that ${ }^{\prime \prime}{ }^{11}$ These figures suggest that employers view appraisals as a key element of performance management, encouraging employees to link their performance to the objectives of the organisation, helping them to respond to changes within the

${ }^{11}$ See http://www.jobs.ac.uk/careers-advice/careers-advice/1349/why-do-we-need-an-appraisal (accessed 2 June 2017). 
industry. From the employee's perspective it is an opportunity to consider their role within the organisation and to debate whether they are achieving objectives and goals previously set.

As is evident, appraisal is common in the workplace. The appraisal process requires employees to consider what their objectives might be and asks them to identify what they think they might achieve and whether any support or additional resources are necessary to help them achieve set targets. As students are not in the workplace, the team considered other ways of setting objectives/targets to be achieved which would directly benefit students and which would involve them in not only looking forward but help them to reflect on their experience. The team decided that setting SMART targets (targets which are Specific, Measurable, Achievable, Realistic and Time bound) would be useful for our purposes as, introduced in the way we did, would enable students to look beyond the 'now' and therefore help them with self-development and career planning. ${ }^{12}$

\section{Adapting Workplace Appraisal to CLE}

At the University of Portsmouth, in an attempt to (as far as possible) replicate the work place, the team has adopted appraisal as part of the assessment process.

${ }^{12}$ M. Morrison, 'History of SMART Objectives' https://rapidbi.com/history-of-smart-objectives (accessed on 7 June 2017). 
The appraisal is made up of three elements: we ask students to set their own objectives; we encourage them to reflect on the year; and we ask them to look forward, taking their learning into the workplace.

\section{Setting Objectives}

In the same way as employees discuss objectives with their manager for the year ahead, at the beginning of the autumn term CLE students are asked to consider their own objectives (student equivalent of SMART targets) for the coming year. Areas often identified by students relate to improvement of one or more of the skills groups discussed above such as assertiveness or case management as well as strategies to deal with prejudice. Students are asked to identify four objectives relating to areas upon which they wish to improve over the coming year. Supervisors ensure that the objectives are all of a similar value in relation to their complexity and the student's ability to achieve them, however, these are the student's own objectives and it is therefore important that they are not contrived. In monthly student/supervisor meetings, supervisors monitor these objectives and students are encouraged to discuss any barriers they may face in achieving their objectives. The meeting provides an opportunity for the students to reflect on the work they are undertaking. Hoping to replicate the working environment discussions related to how the student objectives link to other clinic related activities are held. These discussions help to reinforce in the student's mind the contribution they are making to their own progression and development in the 
CLE units and the value both the unit and the assessment method has in preparing them for the workplace. Having discussed and monitored the objectives during the year, these form the basis of the appraisal interview which occurs towards the end of the academic year and students are required to provide evidence that the objectives they set themselves have been achieved or that they are working towards their achievement. Evidence takes many forms, for example, if a student has initially identified that they feel they need to be more focused in case management, they may bring to the appraisal examples of how the skill has improved during the year. Of course the supervisor has been observing the student's progress throughout the year and their notes reinforce the student's own evidence.

\section{Reflection}

Just as in workplace appraisal, the year as a whole is reviewed at the appraisal meeting with students discussing the challenges they have faced. Reflection is an important part of the assessment. CLE provides a safe environment in which students are able to 'test' their skills and reflecting on the experience provides a platform for future development. 
Forward Reflection

Forward reflection allows students to consider how they might do things differently in the future. This is a much deeper level of learning and has been referred to as transformative learning. ${ }^{13}$ A student may reflect on choices made and, now at the end of the experience, review those choices in the context of any future goals, assessing how the experience has shaped their future decisions. Reflecting forward helps students to consider the impact that this practical method of learning has had on their intellectual, personal or ethical development and enables them to build and develop an action plan in order to support their personal ambitions.

Feedback from students suggests that appraisal is a worthwhile aspect of the CLE experience and that it is effective in encouraging them to focus on selfdevelopment. ${ }^{14}$ In terms of its reliability as an assessment tool, from experience it has become clear that when self-selected objectives are set, students take ownership of these and strive towards their achievement. It could be argued that there is a tension in what the team is trying to achieve by focusing on student contribution and achievement as, when used in an employment situation,

\footnotetext{
${ }^{13}$ King K P, 'A journey of transformation: A model of educators' learning experiences in educational technology' in Pettit JM \& Francis RP (eds) Proceedings of the 43rd Annual Adult Education Research Conference (2002), pp. 195- 200. Available: $<$ https://www.researchgate.net/publication/266332610_A_Journey_of_Transformation_A_Model _of_Educators\%27_Learning_Experiences_in_Educational_Technology $>$.

${ }^{14}$ Information taken from University annual student unit feedback survey May 2016
} 
appraisal is often target driven. It is the team's belief however, that by encouraging contribution and by the student taking ownership of setting and monitoring their own targets by way of self-set objectives and discussing these throughout the process, students are empowered to fulfil their potential using a quasi-workplace model.

\section{Student Satisfaction}

Although at the time of writing 2017 results are not yet available, end of year results from University of Portsmouth Student Satisfaction survey 2016 indicated that of those surveyed $96 \%$ of students agreed to the statement 'the unit makes a positive contribution to my overall course' and overall satisfaction with the unit was $100 \% .{ }^{15}$ The team takes this as confirmation that the students are satisfied with the approach taken and comments on these forms clearly demonstrate that appraisal plays a large part in contributing to student satisfaction, achievement and success.

\section{Conclusion}

The number of clients seeking help from the University of Portsmouth clinics and the increase in the number of students who wish to participate in CLE activities increases year on year which in itself poses a challenge. This coupled with the

15 ibid. 
fact that in April 2017 in its consultation paper ${ }^{16}$ the Solicitors Regulation Authority announced that the requirement for the successful completion of a Legal Practice Certificate prior to qualifying as a solicitor will disappear will have an impact on the way law students are taught and assessed. Under the proposals, as well as undertaking a new Solicitor's Qualification Examination, individuals will be required to undertake work experience. At the time of writing no fixed time period for this is given, however it is thought that this is likely to be between 18 months and 2 years. If these changes do go ahead as proposed, not only will CLE become an increasing challenge/opportunity for universities but the assessment of such programmes will need to be carefully considered. The use of appraisals in University of Portsmouth CLE programmes has become very effective as an assessment tool and it is the team's aspiration that this quasi work related method to assess student achievement in CLE can be continued.

\footnotetext{
${ }^{16}$ https://www.sra.org.uk/sra/consultations (accessed 2nd June 2017)
} 